\title{
Conditions Supporting Funnel Cloud Development in Alaska
}

\author{
Stanley G. Edwin', Nicole Mölders ${ }^{1,2 *}$, Katja Friedrich ${ }^{3}$, Sebastian Schmidt ${ }^{3}$, Richard Thoman ${ }^{4}$ \\ ${ }^{1}$ Department of Atmospheric Sciences, College of Natural Science and Mathematics, University of Alaska Fairbanks, \\ Fairbanks, AK, USA \\ ${ }^{2}$ Geophysical Institute, University of Alaska Fairbanks, Fairbanks, AK, USA \\ ${ }^{3}$ Department of Atmospheric and Oceanic Sciences, University of Colorado at Boulder, Boulder, CO, USA \\ ${ }^{4}$ National Weather Service Forecast Office, NOAA, Fairbanks, AK, USA \\ Email: *cmoelders@alaska.edu
}

How to cite this paper: Edwin, S.G., Mölders, N., Friedrich, K., Schmidt, S. and Thoman, R. (2017) Conditions Supporting Funnel Cloud Development in Alaska. Atmospheric and Climate Sciences, 7, 223245.

https://doi.org/10.4236/acs.2017.72016

Received: February 8, 2017

Accepted: April 22, 2017

Published: April 25, 2017

Copyright $\odot 2017$ by authors and Scientific Research Publishing Inc. This work is licensed under the Creative Commons Attribution International License (CC BY 4.0).

http://creativecommons.org/licenses/by/4.0/

\begin{abstract}
The characteristics and climatology of funnel clouds in Alaska were examined using operational radiosondes, surface meteorological observations, and reanalysis data. Funnel clouds occurred under weak synoptic forcing between May and September between 11 am and 6 pm Alaska Daylight Time with a maximum occurrence in July. They occurred under Convective Available Potential Energy $>500 \mathrm{~J} \cdot \mathrm{kg}^{-1}$ and strong low-level wind shear. Characteristic atmospheric profiles during funnel cloud events served to develop a retrieval algorithm based on similarity testing. Out of more than 129,000 soundings between 1971 and 2014, 2724, 442, and 744 profiles were similar to the profiles of observed funnel cloud events in the Interior, Alaska West Coast, and Anchorage regions. While the number of reported funnel clouds has increased since 2000, the frequency of synoptic situations favorable for such events has decreased.
\end{abstract}

\section{Keywords}

Alaska Funnel Clouds, Funnel Cloud Climatology, Similarity Retrieval Algorithm, Mesoscale Forcing for Funnel Cloud Formation in Alaska

\section{Introduction}

Over the last decade, Alaska funnel clouds received increasing attention from the media and public because of the increase of funnel cloud reports and interest in climate change [1]. Most reports come from the public in populated areas, weather forecasters or trained spotters, and passengers and pilots within flight corridors. Less than $2 \%$ of Alaska is developed (Figure 1), meaning that proba- 


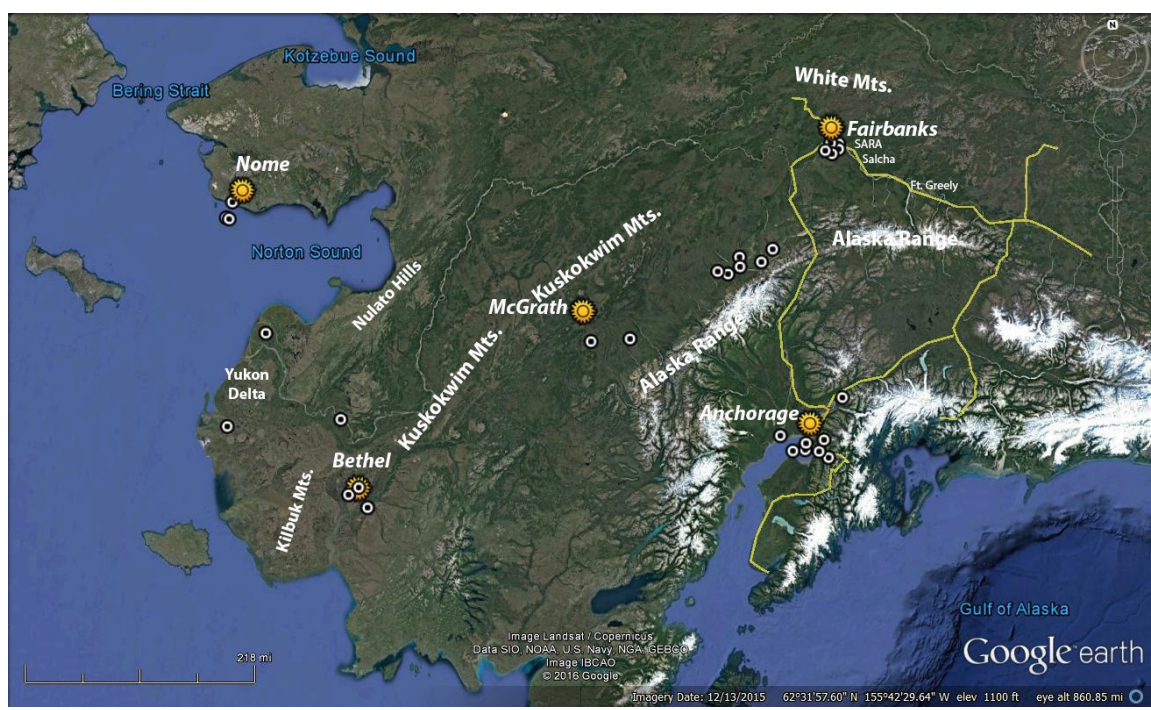

Figure 1. White circles denote the location of funnel cloud sightings in Alaska from 1955 to 2014. Yellow stars indicate radiosonde launch sites. Chartreuse lines are the paved roadnet. Names refer to locations mentioned in the text. SARS is the Small Arms Range Alaska. The Brooks Range is North of the map.

bility is high for events to remain unreported in unpopulated areas [2]. Furthermore, only eight operational Weather Surveillance Radar 88 Doppler (WDR-88D) radars exist in Alaska leaving large areas without radar coverage.

Alaskans have followed the reports of funnel clouds with great interest and concern as funnel clouds mean a threat to air traffic [1]. Due to Alaska's vast land and low population density ( 0.5 persons per square kilometer), many villages are off the road network (Figure 1). Using small aircrafts to reach one of the three major cities (Anchorage, population 300,950, Fairbanks 32,324, Juneau 32,660 ) for shopping, medical care, or visiting is as common to Alaskans like using subways, trams, taxis, and busses for metropolitan residents elsewhere in the United States. These aircrafts, which fly below $3 \mathrm{~km}$ above ground level, also deliver general supply, mail service, and medical transport to/from remote settlements [1].

Three major mountain ranges, the Brooks Range, White Mountains, and Alaska Range, run from west to east. The Brooks Range is the northernmost, and the Alaska Range, the southernmost (Figure 1). Between the ranges are boreal forest-covered wide valleys.

This complex topography of high glacier-covered mountains, steep mountain passes, and wide, low populated valleys exposes aviation to several threats. In mountainous terrain, like along the coast, weather can change quickly [3]. Fog can close mountain passes and valleys, and thunderstorms may build in air corridors, and in-cloud icing may occur [4]. Funnel clouds add another potential flight hazard [1].

No forecasting system exists for funnel clouds in Alaska [1]. The sighting and software detection protocols for tornadoes used by the National Weather Service (NWS) were developed for the Central United States. There, the majority of 
funnel clouds are associated with tornadoes and develop in high-reaching severe thunderstorms [5] [6]. As our analysis showed, none of the funnel cloud sightings in Alaska were associated with these types of mesoscale systems [1]. Consequently, the applied protocols may of limited or no use for Alaska.

Understanding the characteristics, forcing, formation and climatology of Alaska funnel clouds is vital towards forecasting them. The goal of this study was to establish a funnel cloud climatology based on radiosonde and reanalysis data to shed light on the characteristics and forming mechanisms. We hypothesized the following: a) Funnel clouds occur under distinct weak synoptic scale conditions that permit formation of topography induced mesoscale systems; b) The vorticity required to generate funnel clouds is due to interaction of the synoptic scale wind field and local wind systems. Consequently, similarity criteria can be determined to identify past and future potential funnel cloud events. While the latter is of interest for forecasting, the former permits assessment of frequency of funnel cloud occurrence to evaluate the increase in funnel cloud reports events since 2000.

\section{Datasets and Methods}

\subsection{Funnel Cloud Reports}

The Alaska NWS has collected funnel cloud reports since 1955 [7]. This dataset excludes tornadoes except for persuasive purposes on radar detection capabilities. The dataset encompassed 43 funnel cloud reports between 1955 and 2014. Most reports came with broad location descriptions instead of geographic coordinates. We discarded two sightings due to missing date, time, and location data. We excluded water sprouts or funnel clouds spotted over ocean from our study.

All remaining 41 funnel cloud events occurred near populated areas, along air corridors, along the coasts and within major valleys (Figure 1). Under consideration of the Alaska climate divisions [3] [8], we grouped the 41 reported events into three regions of similar atmospheric and landscape characteristics: a) The Interior with Fairbanks and McGrath characterized by the Tanana Valley with mountains to the North and South; b) the Alaska West Coast with Nome and Bethel influenced by the Beaufort Sea; and c) the Anchorage area governed by mountains and the northern coast of the Gulf of Alaska.

\subsection{Soundings, Weather Radar, Reanalysis, and Surface Observations}

In Alaska, operational twice daily (00 UTC, 12 UTC) radiosonde launches started in the 1940s. Archiving started 1948. The launch time changed in 1957. Since then, radiosonde data are available in winter at $2 \mathrm{pm}$ Alaska Standard Time (AKST $=$ UTC- $8 \mathrm{~h}$ ) the previous day and 2 am the same day, and in summer at $3 \mathrm{pm}$ the previous day and 3 am Alaska Daylight Saving Time the same day $($ AKDT $=$ UTC-9 h). The soundings provide pressure, height, temperature, wind speed and direction, and dew-point temperature.

Prior to 1971, most dew-point temperature data are missing. Due to technical 
issues, there are periods of missing dew-point temperature data or otherwise incomplete radiosonde data between 1989 and 1999. Out of the 41 funnel cloud reports, 32 events occurred within \pm 6 hours of the launch. Of these 32 sightings, 19 occurred within \pm 2 hours of a launch, and inside a 40 - $\mathrm{km}$ radius of the site (Figure 1).

In Alaska, operational radar observations started in 1993, archiving in 1997. Between 1997 and 2014, ten funnel cloud events occurred within the 230-km radar range (four at Anchorage, two at Fairbanks, two at Bethel, two at Nome). Only four of them had latitude and longitude coordinates [7] for locating and analysis in radar data.

In Alaska, surface observations are sparse. Hourly observations of near-surface wind direction from the National Climate Data Center were available for some locations for limited time. We used the National Center for Environmental Protection/National Center for Atmospheric Research global reanalysis data [9] [10] at 300, 500 and $1000 \mathrm{hPa}$.

\subsection{Data Processing}

Progress in measurement techniques, digital possibilities, and radiosonde-location retrieval increased the accuracy and data resolution over time [11]. Consequently, the radiosonde dataset is inhomogeneous with respect to data quality, accuracy, and quantity. The increased data quantity means an increase in vertical and temporal resolution during an ascent.

Investigations of climatology and changes in climatology require data of same or at least comparable resolution, accuracy, and quality [2]. We homogenized the radiosonde dataset by introducing mandatory pressure ranges (Table 1), in which we analyzed the observed funnel cloud events to determine profile characteristics and later to retrieve profiles like those observed during funnel cloud events.

To identify the synoptic scale situations under which funnel clouds occurred, we analyzed the reanalysis maps at 300, 500 and $1000 \mathrm{hPa}$ for all 41 observed events. We made composite maps of synoptic situations of observed funnel cloud events for each region.

We also calculated composite maps using the reanalysis data of those days identified by the similarity retrieval algorithm (see Section 2.5) as potential funnel cloud events. Comparison of the composites of retrieved and observed funnel cloud events served to evaluate whether the retrieved events represented synoptic conditions in a mesoscale sense (weak synoptic forcing, strong wind shear in $\mathrm{ABL}$, close to or saturated air in the lower troposphere with strong wind shear in the $\mathrm{ABL}$ ) like on days with funnel cloud events. If so, the retrieval algorithm could identify synoptic situations suitable for funnel cloud events in numerical weather prediction (NWP) data.

\subsection{Characteristics of Observed Funnel Cloud Events-Baseline Profiles}

Theoretically (cf. [5] [12] [13]), the concentration of funnel cloud reports over 
Table 1. Baseline profile limits based on the sounding analysis: Mandatory pressure (p) ranges required to have valid measurements for being considered in the determination of the baseline profile limits of funnel cloud characteristics for the three regions for air temperature $(\mathrm{T})$, dew-point temperature $\left(\mathrm{T}_{\mathrm{d}}\right)$, and wind speed $(\mathrm{v})$. The closest radiosonde site in a region was used except for events that fell between two sites. Baseline profiles and limits were then determined for the same event for both sites. In the columns named "events between Fairbanks and McGrath" and "events between Bethel and Nome," the first and second columns refer to the first and second mentioned sites. For further details see text.

\begin{tabular}{|c|c|c|c|c|c|c|c|c|}
\hline \multirow{3}{*}{$\begin{array}{c}\text { Regions } \\
\begin{array}{c}\text { Sounding } \\
\text { site }\end{array} \\
\mathrm{p}(\mathrm{hPa})\end{array}$} & \multicolumn{4}{|c|}{ Interior } & \multicolumn{3}{|c|}{ Alaska West Coast } & \multirow{3}{*}{$\begin{array}{c}\text { Anchorage area } \\
\text { Anchorage }\end{array}$} \\
\hline & Fairbanks & McGrath & Fairbanks ar & d McGrath & Bethel & Bethel a & ad Nome & \\
\hline & \multicolumn{7}{|c|}{$\mathrm{T}\left({ }^{\circ} \mathrm{C}\right)$} & \\
\hline $250-150$ & $-60.8--43$ & $-71.2--54$ & $-63.9--50.5$ & $-66.2--58.6$ & $-71.4--52.8$ & $-70--57.4$ & $-71.7--56.4$ & $-78.0--63.0$ \\
\hline $350-250$ & $-52.2--44$ & $-55.4--48$ & $-56.6--40$ & $-53--49.1$ & $-58.2--45.3$ & $-57.7--49.6$ & $-58.7--47.3$ & $-77.5--42.0$ \\
\hline $350-250$ & $-52.2--44$ & $-47.8--26$ & $-50.8--28.6$ & $-36.6--31.2$ & $-53.9--32.2$ & $-41.7--32.9$ & $-43--33.7$ & $-50.0--38.3$ \\
\hline $550-450$ & $-24.1--16$ & $-27.9--21$ & $-53.1--14.9$ & $-47.9--10.3$ & $-48.1--18.9$ & $-31.1--19.7$ & $-40.4--17.4$ & $-42-25.7$ \\
\hline $738-650$ & $-6.4--1$ & $-11.6--5$ & $-14.5--2.1$ & $-4.4--7.5$ & $-14.5--5.5$ & $-12.6--4.6$ & $-18.2-.5$ & $-36.0--1.2$ \\
\hline $888-813$ & $4.4-11$ & $-1.6-7$ & $-4.6-3.4$ & $-0.5-1.7$ & $-0.5-1.5$ & $-1.1-3.6$ & $-0.8-5.7$ & $-12.0-6.4$ \\
\hline $963-888$ & $9.1-12$ & $6-11$ & $2-6.8$ & $-0.5-6.7$ & $1.1-9.2$ & $1.6-7.8$ & $2.1-9.8$ & $-9.0-4.2$ \\
\hline$>963$ & $10.8-21$ & $14-21.3$ & $5.3-9.9$ & $5.1-9.7$ & $6.5-12.3$ & $5.6-9.6$ & $2.7-12.9$ & $-0.8-9.4$ \\
\hline $\mathrm{p}(\mathrm{hPa})$ & \multicolumn{8}{|c|}{$\mathrm{T}_{\mathrm{d}}\left({ }^{\circ} \mathrm{C}\right)$} \\
\hline $250-150$ & $-77.6--53$ & $-57.5--43$ & $-56.7--51.4$ & $-57.3--50.3$ & $-57.2--45.1$ & $-49--45$ & $-56.7--42$ & $-53.8--42.0$ \\
\hline $350-250$ & $-61--50$ & $-45.3--45$ & $-47.6--45.2$ & $-47--45.1$ & $-48.3--38.4$ & $-51.9--42.6$ & $-48.3--45$ & $-53.5--45.3$ \\
\hline $350-250$ & $-61--50$ & $-30.3--20$ & $-32.3--29$ & $-32.2--29.1$ & $-33.4--25.7$ & $-37.6--29.6$ & $-34.9--30.7$ & $-44.0--31.4$ \\
\hline $550-450$ & $-27.8--21$ & $-20--16$ & $-23.2--16.3$ & $-24.4--16.2$ & $-22.6--13.7$ & $-26--17.5$ & $-23.8--18.4$ & $-32.0--19.6$ \\
\hline $738-650$ & $-9.5--1$ & $-2.3-0$ & $-8.9--2.2$ & $-9.9--3.2$ & $-6.6--0.6$ & $-9.2--3.7$ & $-7.3--2$ & $-13.0--4.0$ \\
\hline $888-813$ & $0.2-7$ & $8.2-12$ & $2.6-8.3$ & $-0.4-5.6$ & $1.7-8.8$ & $-0.4-6.4$ & $2.2-7.2$ & $-2.4-5.4$ \\
\hline $963-888$ & $4.4-12$ & $14.2-16$ & $6-13.9$ & $3.9-11.2$ & $4.4-13.9$ & $3.7-10.6$ & $7.2-12.6$ & $-0.2-13.3$ \\
\hline$>963$ & $9.6-15$ & $6.8-29$ & $6-17.5$ & $5.9-13.5$ & $9-22.5$ & $8.19-18.7$ & $9.7-20.8$ & $9.5-15.3$ \\
\hline $\mathrm{p}(\mathrm{hPa})$ & \multicolumn{8}{|c|}{$\mathrm{v}\left(\mathrm{m} \cdot \mathrm{s}^{-1}\right)$} \\
\hline $250-150$ & $0.8-12$ & $0.9-11$ & $1.3-13.5$ & $6.6-25.9$ & $7.8-42$ & $0.6-9$ & $0-18.3$ & $2.2-23.4$ \\
\hline $350-250$ & $5.2-6$ & $5.6-6$ & $0-13.5$ & $5.2-31.7$ & $9.4-42.4$ & $2.6-20.8$ & $0-26$ & $26.9-31.7$ \\
\hline $350-250$ & $5.2-6$ & $1-11$ & $4-11.4$ & $4.1-26$ & $8.2-27.5$ & $3.4-14.5$ & $0.7-21$ & $5.0-20.2$ \\
\hline $550-450$ & $0-8$ & $0-12$ & $1-15.7$ & $3.2-24.5$ & $4.6-21.2$ & $2-12.5$ & $2.4-14.6$ & $1.8-15.2$ \\
\hline $738-650$ & $0-8$ & $0.9-5$ & $0-21.9$ & $2.4-14.3$ & $1.6-13.5$ & $3.5-10.4$ & $1.5-14.6$ & $1.6-8.0$ \\
\hline $888-813$ & $2.4-4$ & $0.4-2$ & $0-16.3$ & $0-15.4$ & $2.7-6.3$ & $2-12.2$ & $2.4-7.1$ & $0.0-11.0$ \\
\hline $963-888$ & $0.0-1.7$ & $0-8$ & $0-14.8$ & $2-16.8$ & $1.1-3.5$ & $2.3-12.4$ & $0.9-6.6$ & $0.0-18.4$ \\
\hline$>963$ & $1.6-4$ & $0-3$ & $0-4.6$ & $0-9.5$ & $0.7-3.1$ & $0.8-7.3$ & $2.3-5.5$ & $2.0-6.4$ \\
\hline
\end{tabular}

the summer and between 11 am and 6 pm AKDT as well as the lack of thunderstorms near the reported location suggested that terrain- and ocean-induced circulations may be key in funnel cloud formation. During funnel cloud events, lifting condensation levels were between 1000 and $800 \mathrm{hPa}$. Close to or saturated conditions existed in a layer of $500 \mathrm{~m}$ to $2 \mathrm{~km}$ thickness (Figure 2). 


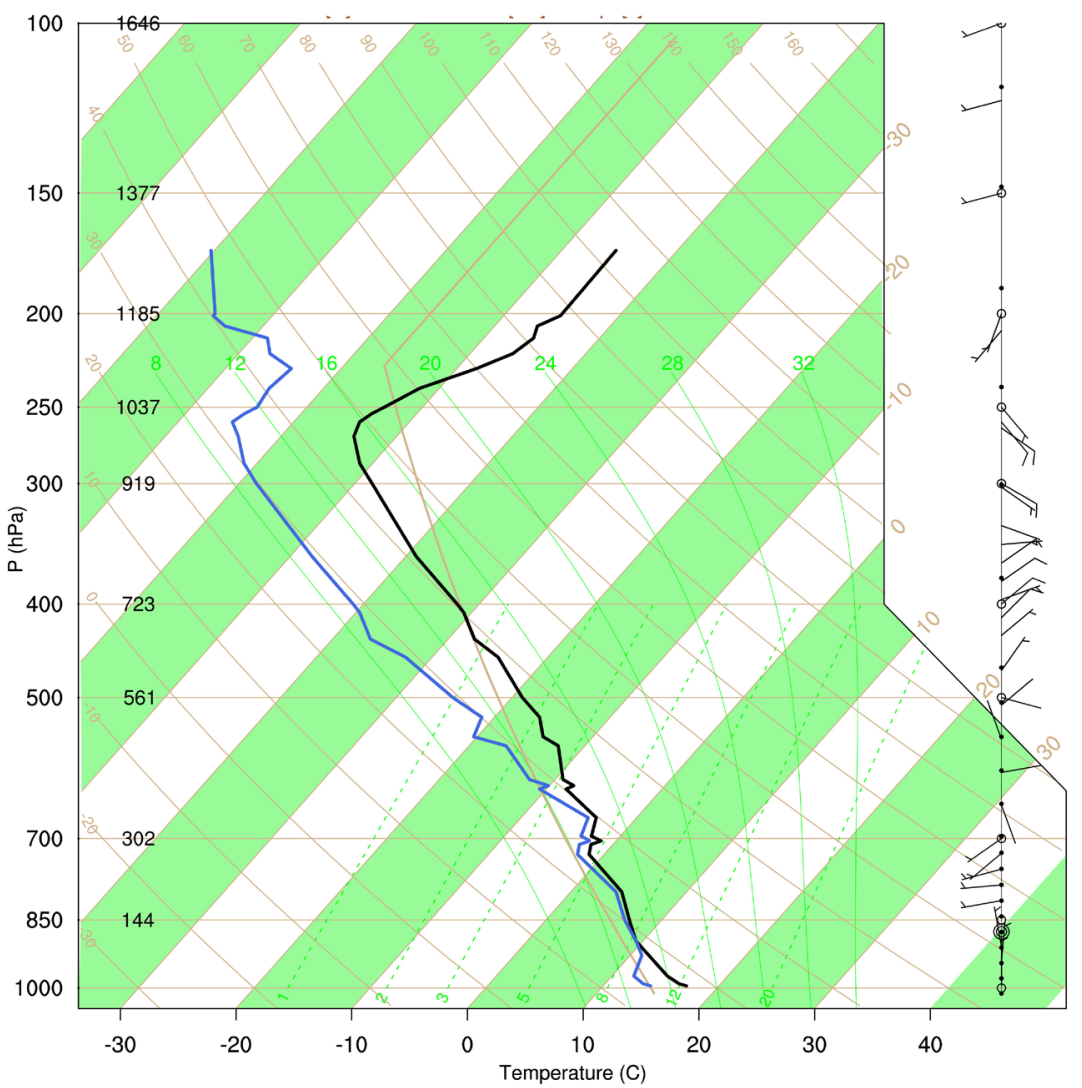

(a)

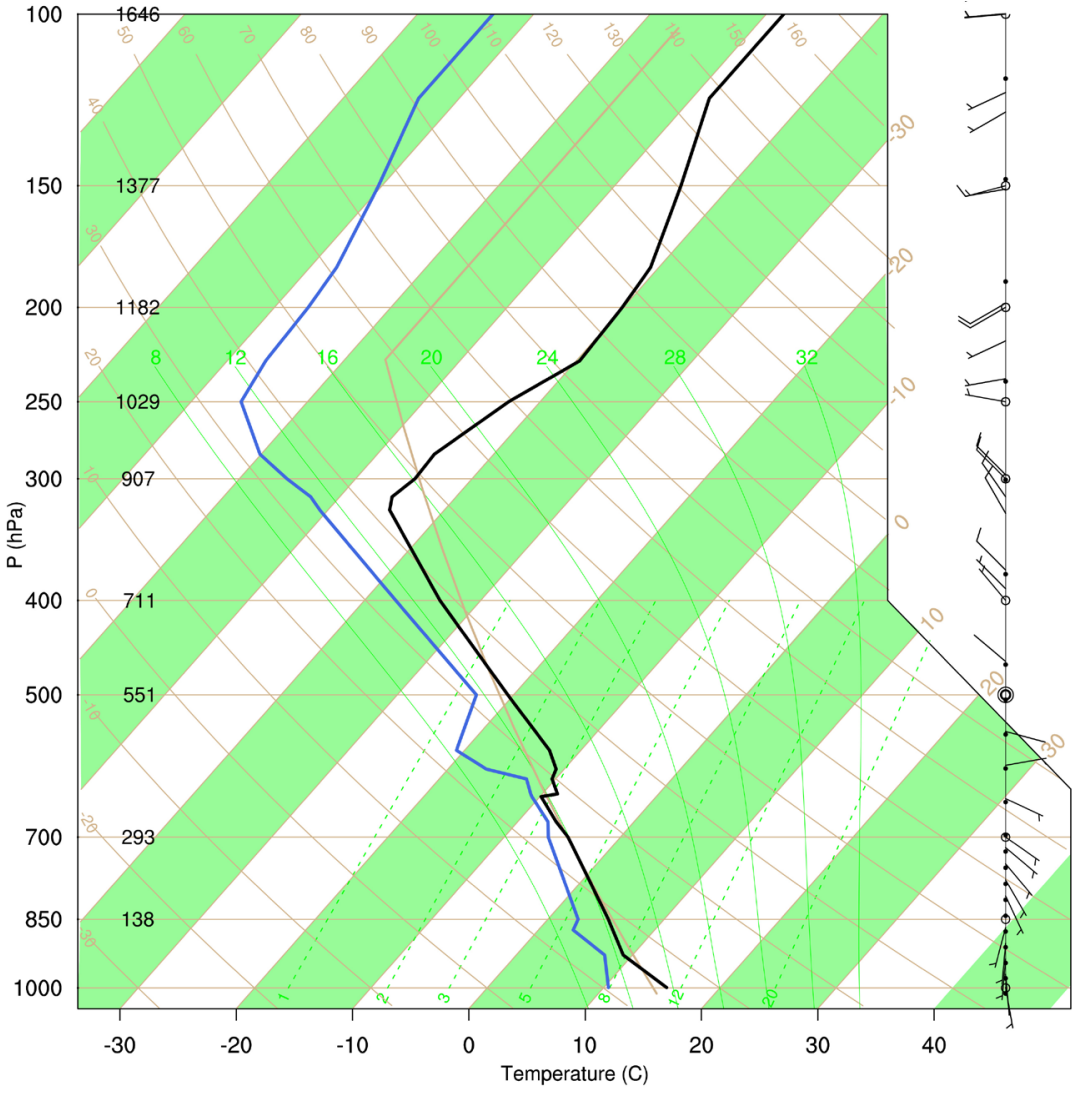

(b) 


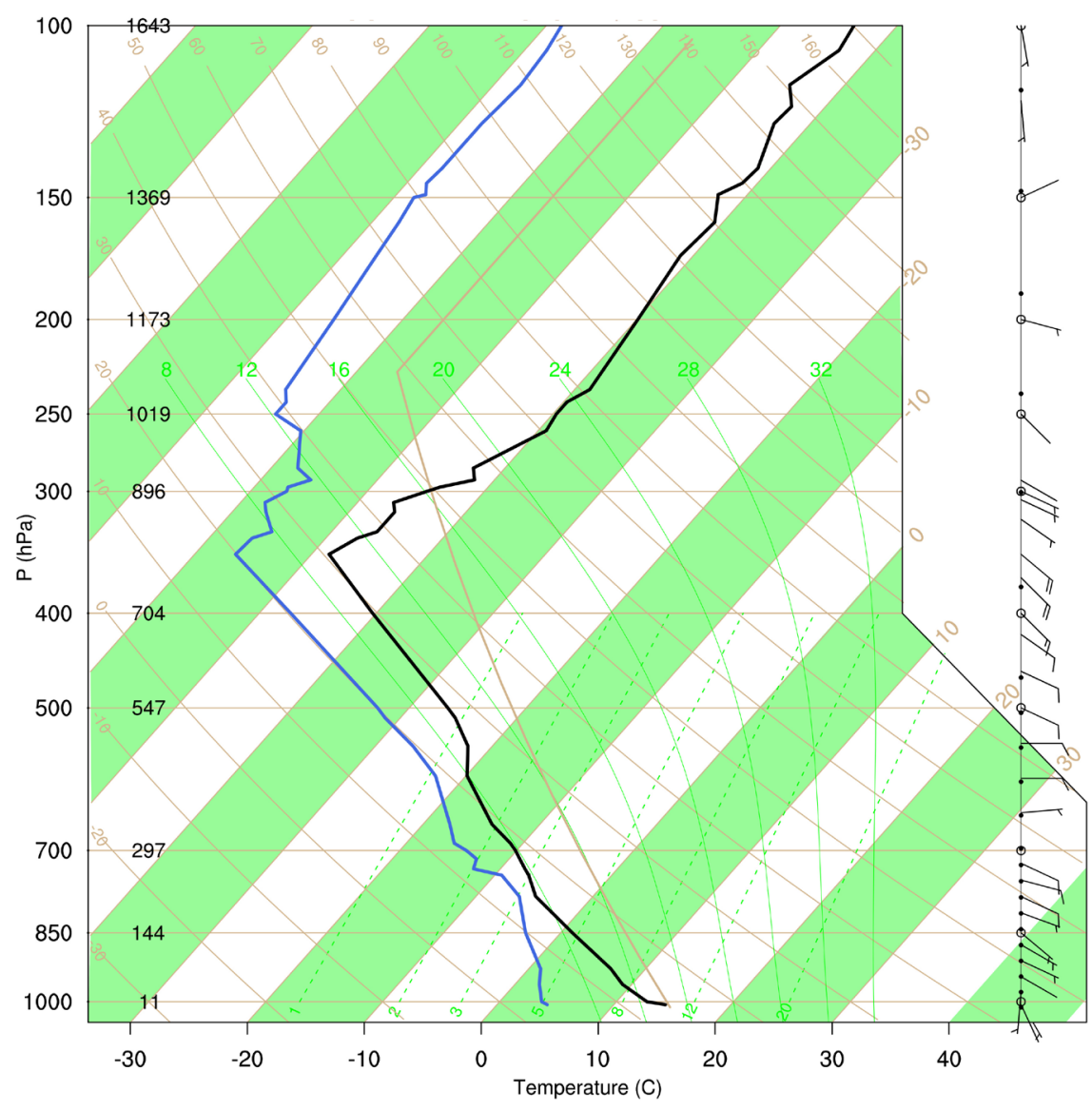

(c)

Figure 2. Examples of radiosonde profiles on days with funnel cloud sightings (a) at Fairbanks in the Interior on July 22, 201012 UTC; (b) at Bethel in the Alaska West Coast region on July 29, 200400 UTC and (c) close to Anchorage on July 1, 201200 UTC. At the time of the radio soundings, convective available potential energy (CAPE) values were $1403 \mathrm{~J} \cdot \mathrm{kg}^{-1}, 1234 \mathrm{~J} \cdot \mathrm{kg}^{-1}$, and $939 \mathrm{~J} \cdot \mathrm{kg}^{-1}$, lifting condensation levels were at $950 \mathrm{hPa}, 928$ $\mathrm{hPa}$, and $868 \mathrm{hPa}$ and cloud precipitable water was $3 \mathrm{~cm}, 2 \mathrm{~cm}$, and $1 \mathrm{~cm}$ at Fairbanks, Bethel, and Anchorage, respectively. The actual funnel clouds occurred in Fairbanks on 2010-07-22 9:47 am, and between Bethel and Nome on 2004-07-28 at 1:25 pm AKDT. No exact time was reported for the funnel cloud in the Anchorage region.

To understand the interaction of forcing at the synoptic scale and smaller mesoscale, we used the soundings closest to the observed funnel cloud event to assess the typical atmospheric conditions. Since dew-point temperatures were widely unavailable in the dataset prior to 1971, the number of funnel cloud events reduced to a total of 26 events with 8 for the Anchorage, 13 for the Interior, and 5 for the Alaska West Coast area.

In these regions, air and ground temperature conditions vary widely from May to September [3]. Given the small sample sizes for each region, means and standard deviations failed to represent the range of funnel cloud conditions and to create a representative baseline profile.

Therefore, for any pressure level within the limits of one of the pressure ranges, the associated height, air and dew-point temperature were stored for the 
funnel cloud events for each radiosonde site. In case of funnel cloud sightings between two radiosonde stations (Fairbanks and McGrath, Bethel and Nome), we stored baseline profiles for both sites.

In a next step, the maximum and minimum limits of the stored variables were determined from all data available for that pressure range and radiosonde site. Table 1 lists the resulting minimum and maximum profiles that give the range of baseline profiles of funnel cloud events in the respective regions.

Since the events occurred in different places (Figure 1) with different topography (e.g. valley height, slope direction, steepness), wind direction differed largely among events in the atmospheric boundary layer (ABL). Therefore, no baseline profile ranges were determined for wind direction.

\subsection{The Similarity Retrieval Algorithm}

Once the baseline profile limits were derived, we applied the following retrieval algorithm for similarity testing. We searched the entire sounding database between May and September between 1971 and 2014 for other days with profiles that fulfill the baseline profile limits given in Table 1.

For profiles fulfilling these conditions, CAPE was calculated. Since reported funnel cloud events that were close in time or space to the launch time and site had CAPE about $500 \mathrm{~J} \cdot \mathrm{kg}^{-1}$ or higher (Figure 3(a)), all those profiles falling within the baseline profile limits (Table 1 ) with CAPE $>500 \mathrm{~J} \cdot \mathrm{kg}^{-1}$ were considered as having atmospheric conditions that could potentially lead to a funnel cloud event. Note that the atmospheric conditions during the funnel cloud event, which occurs close to the site and close to the launch time, are represented better by the observed profile than the atmospheric conditions of events farther away or with a large difference between the time of the sounding and event.

In the case of funnel clouds between two sites, the similarity retrieval algorithm screened for potential events using the data of both radiosonde sites and the baseline profile limits determined for funnel clouds between the sites (Table 1). For atmospheric conditions to be considered as being like those during funnel cloud events occurring between the two sites, at each site, the profile had to fall within the limits identified for that respective site for "events between sites," and CAPE had to exceed $500 \mathrm{~J} \cdot \mathrm{kg}^{-1}$ at one site. For more details, see [1].

\section{Frequency of Funnel Clouds}

Four funnel cloud events occurred between 1950s and 1960s, 12 in the 1980s and 1990s, and 26 between 2000 and 2014 [7]. All events that occurred close in space or time to the location of the radiosonde site or time of the sounding had CAPE of about or more than $500 \mathrm{~J} \cdot \mathrm{kg}^{-1}$ (Figure 3(a)). Most funnel cloud events occurred between May and September with a peak in July (Figure 3(b)), and between $11 \mathrm{am}$ and $6 \mathrm{pm}$ AKDT. Since funnel clouds occurred in various months and at different times in the diurnal cycle, the ambient conditions during these events varied over a broad range of air and dew-point temperatures (Table 1).

In the Interior, 13 funnel clouds were reported between 1955 and 2014. Near 


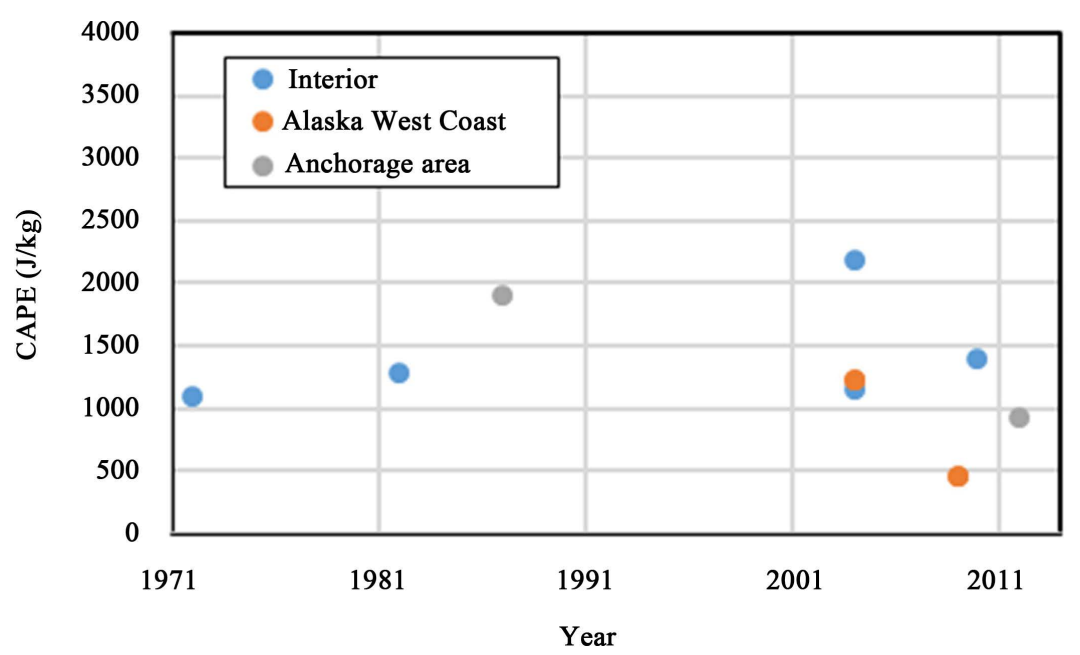

(a)

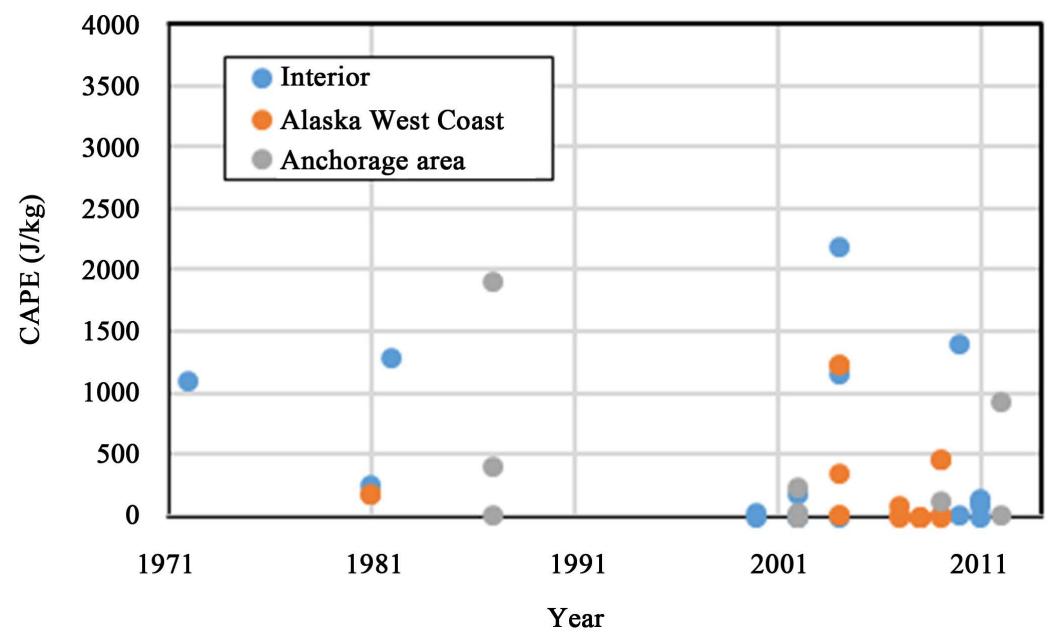

(b)

Figure 3. Frequency of observed funnel cloud events (circles) and their CAPE (a) within 2 hours of the radiosonde sounding or close to the site; (b) all events for which radiosonde data were available no matter of the temporal or spatial distance from the launch time and site. A circle corresponds to one event each. The gaps between 1989 and 1999 are due to erroneous dew-point temperature data and missing data.

Fairbanks, three funnel events occurred in the 80s and two in the new Millennium. One event occurred in May, three in July, and one in August. Near McGrath, two funnel cloud sightings occurred in July. Six funnel cloud events, three in July, and August each occurred between Fairbanks and McGrath. Here, all events, but one were between 9 am and 6 pm AKDT.

In the Alaska West Coast area, five funnel cloud events occurred near Bethel in the new Millennium, in the afternoon to early evening, with one in June, three in August, and one in September. Two of the five sightings were on the same day late in August. Six events occurred between Bethel and Nome, of which all but one were in the new Millennium.

Eight funnel cloud events were reported between May and August near Anchorage. All events occurred between 7:30 am and 6 pm AKDT. 
The similarity retrieval algorithm identified 2724,442 , and 744 profiles like those of funnel cloud events in the Interior, Alaska West Coast, and Anchorage region, respectively (Figure 4). In the Interior, 1303, 417, and 1004 potential funnel cloud events were found when searching the radiosonde data of Fairbanks, the combined data of Fairbanks and McGrath, and those of McGrath. In the Alaska West Coast region, 404 potential funnel cloud events were retrieved from the radiosonde data of Bethel, and 38 in the combined data of Bethel and Nome.

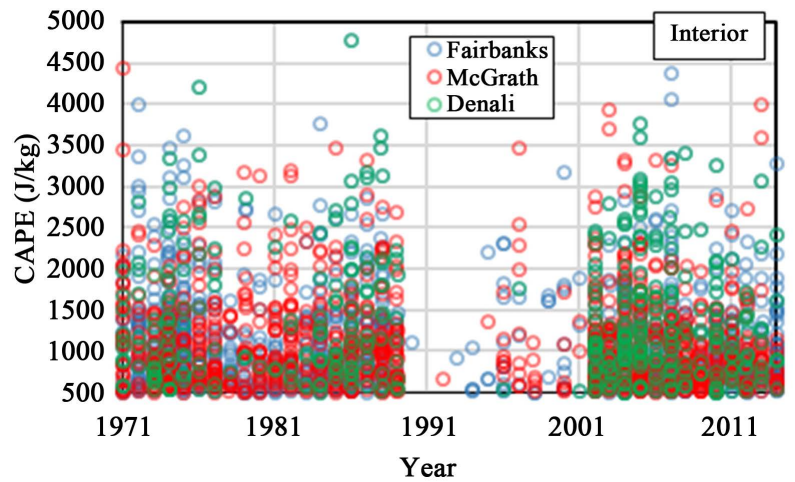

(a)

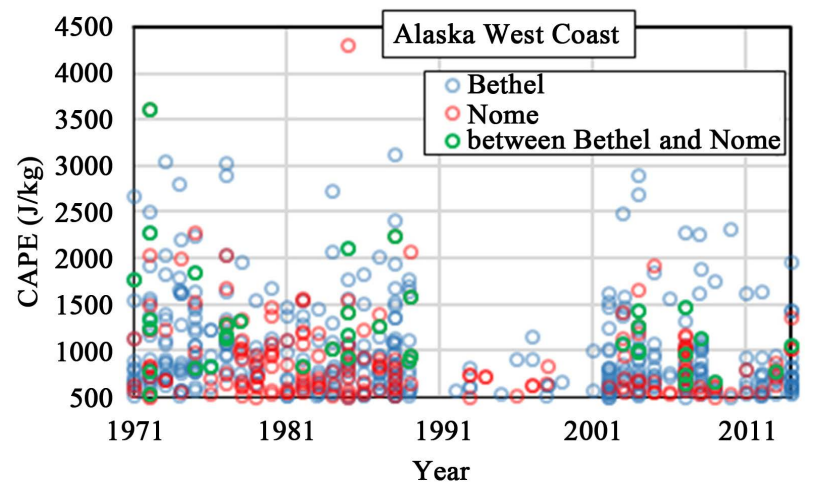

(b)

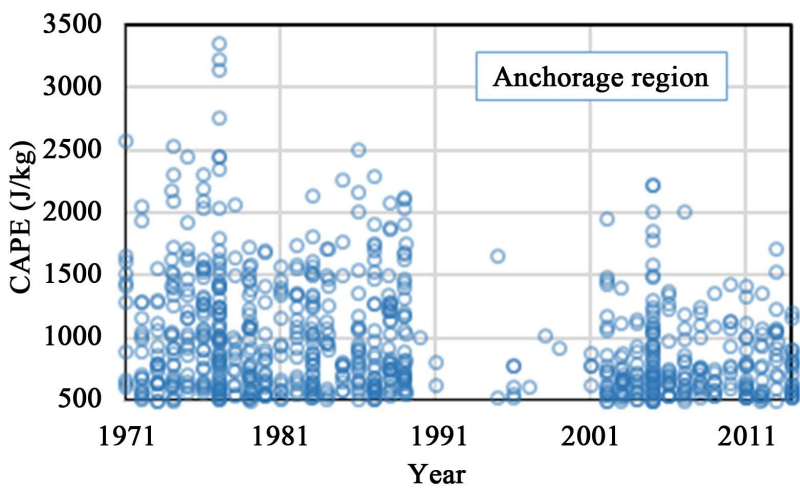

(c)

Figure 4. Frequency of retrieved funnel cloud events (circles) and their CAPE for the (a) Interior; (b) Alaska West Coast; and (c) Anchorage region between 1971 and 2014. A circle corresponds to one event each. The gaps between 1989 and 1999 are due to erroneous dew-point temperature data and missing data. Legends differ from Figure 3. 
The retrieval algorithm identified more funnel cloud events prior to 1989 compared to after 2000. However, the number of observed funnel clouds has increased after 2000. If the retrieval algorithm works, these findings suggest that the NWS' funnel-cloud observation record is certainly biased by the increase in population and availability of devices for documentation.

No circulation pattern in the Doppler velocity could be found in the radar observations mainly due to the coarse temporal or spatial resolution of the radar and due to the blocking of the radar beam in the complex terrain. Nevertheless, the radar data indicated that no thunderstorms were present during the time and near the funnel cloud location.

\section{Environmental Conditions during Observed and Retrieved Funnel Cloud Events}

We analyzed the synoptic (mesoscale $\alpha$ ) and mesoscale $\beta / \gamma$ conditions during reported funnel cloud events and compared those to the synoptic and mesoscale $\beta / \gamma$ conditions during retrieved funnel cloud events. The goal of this analysis was twofold: a) Evaluate the similarity retrieval algorithm and determine if the algorithm might be useful for identifying days of potential funnel cloud occurrence; and b) understand under which synoptic and mesoscale conditions funnel clouds might form, which could guide a more detailed analysis in the future.

\subsection{Interior}

During the observed funnel cloud events, the synoptic scale forcing was weak over the Interior throughout the troposphere. At $300 \mathrm{hPa}$, a common feature was a strong gradient in geopotential height south of the Alaska Range over the northern Gulf of Alaska and a weak gradient over the Interior (Figure 2(a)). The polar jet was located far south over the Gulf of Alaska with a west to east orientation parallel to the northern coast of the Gulf of Alaska. Per the reanalysis, at $500 \mathrm{hPa}$, the gradient winds came from the south, advecting air from the Gulf of Alaska across the Alaska Range towards the Tanana Valley, while near-surface winds blew west to east, up the Tanana Valley (Figure 5(a)). Conditions were zonal and quasi-stationary with respect to the temperature conditions above the $\mathrm{ABL}$. Inversions were visible at different heights between 700 and $500 \mathrm{hPa}$ in the Skew-T diagrams of all observed funnel cloud events (e.g. Figure 2(a)).

In all observed funnel cloud events, the lower troposphere was moist or saturated; while the upper troposphere was relatively dry (e.g. Figure 2(a), Table 1). The radiosonde profiles showed strong wind shear, but no common wind direction in the ABL and mid-troposphere. The latter is because the observed events occurred at different locations with different exposure and steepness of slopes.

The composite surface synoptic maps of retrieved and observed funnel cloud events were similar in a mesoscale sense (e.g. Figure 5(a) and Figure 5(b)). Individual mid- and upper air maps suggested two weak synoptic scale weather conditions were favorable for funnel cloud events in the Interior: a) A highpressure system over the Beaufort Sea including the North Slope with low pres- 

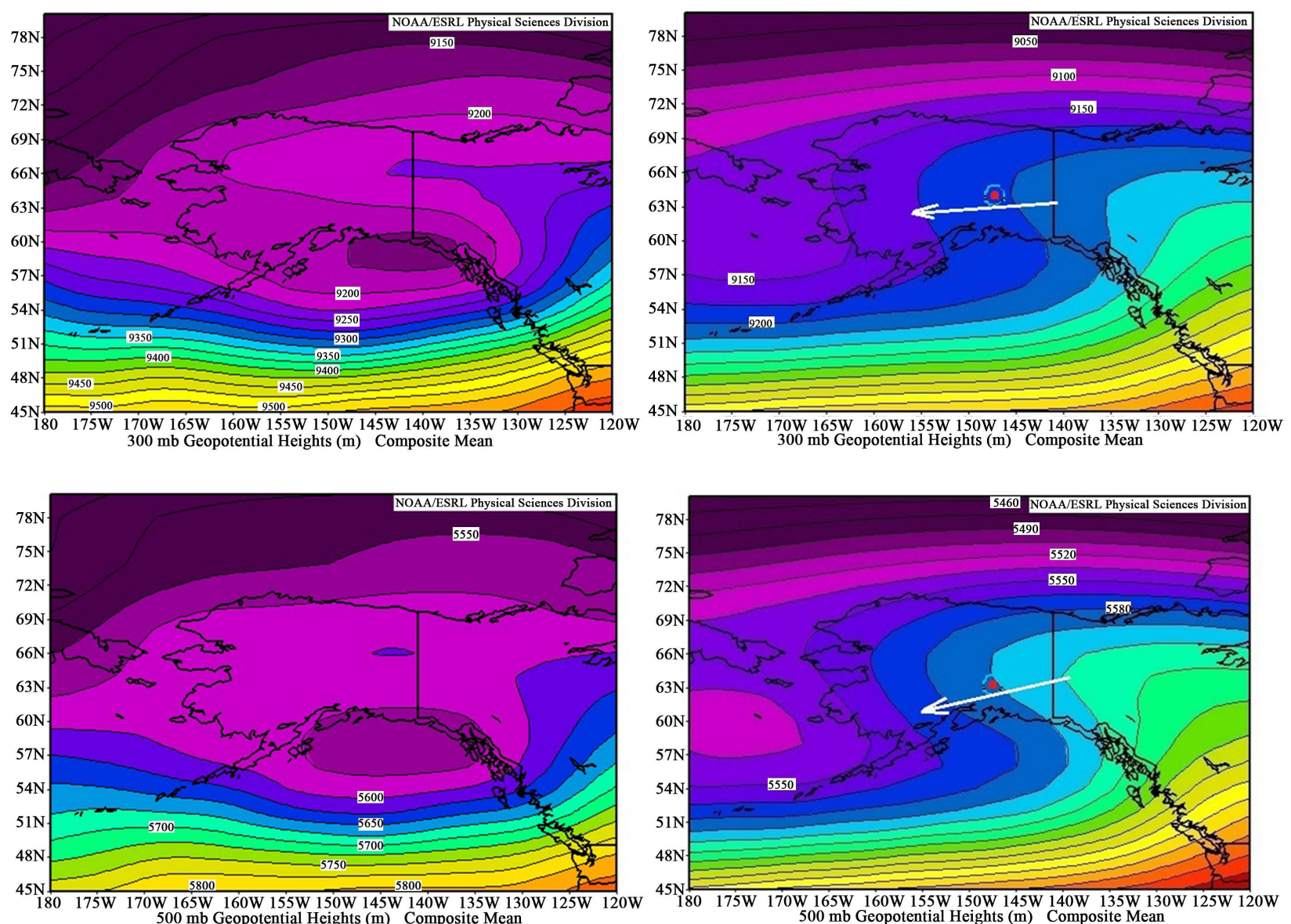

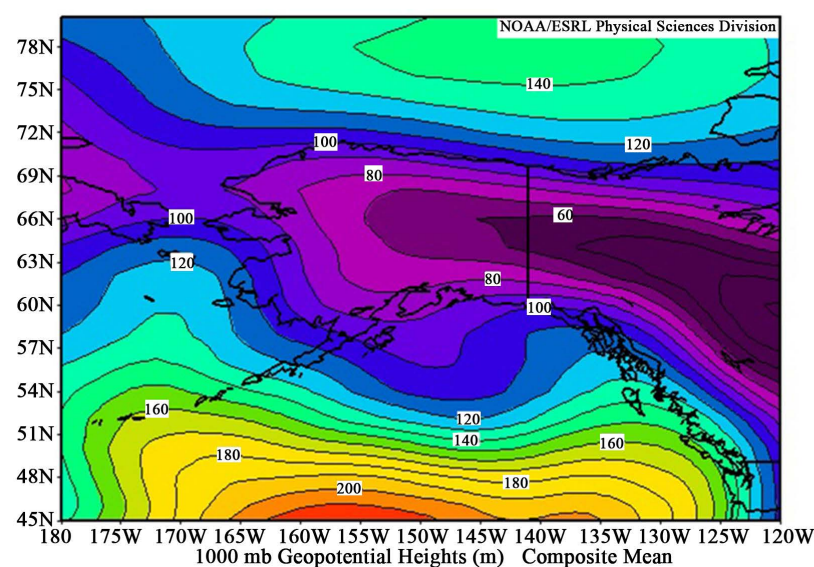

(a)

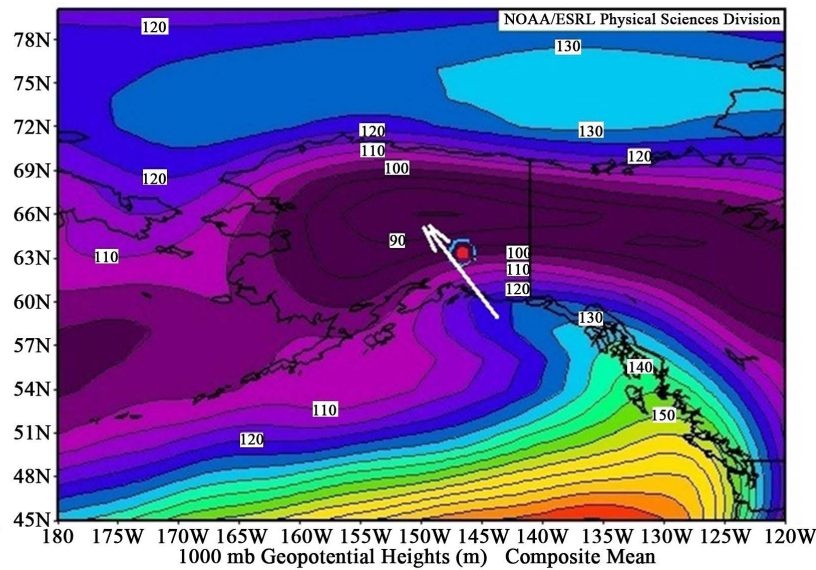

(b)

Figure 5. Composites of reanalysis data showing geopotential heights at $300 \mathrm{hPa}$ (top panel), $500 \mathrm{hP}$ (middle panel), and $1000 \mathrm{hPa}$ (lower panel) on days of (a) observed; and (b) retrieved funnel cloud events in the Fairbanks region of the Interior. The synoptic situations for events around McGrath, and between McGrath and Fairbanks look similar in a mesoscale sense (therefore not shown).

sure over the Gulf of Alaska or b) a low off the Pacific Northwest coast with marginal pressure differences north of the Alaska Range. Consequently, discrepancy between the composites from retrieved and observed events in the midand upper troposphere was expected (e.g. Figure 5(a) and Figure 5(b)). 


\subsection{Alaska West Coast}

On days with funnel cloud events, all radiosonde temperature profiles, but one showed an inversion in the ABL (Figure 2(b)) suggesting the involvement of a sea-breeze system at least for events observed close to the coast (Figure 1). Unfortunately, the few surface meteorological sites in the Alaska West Coast area were a) too far away from the coast to examine for landward penetration of a sea breeze, b) too far away from the funnel cloud event, or c) missing data during the event.

On all days with funnel cloud events, the synoptic scale forcing at 1000 and $500 \mathrm{hPa}$ was weak (Figure 6(a)). The surface map showed high pressure over the Gulf of Alaska and low pressure over the Chukchi Sea. Depending on the position of these pressure systems, a northerly or southerly wind blew parallel to the Alaska West Coast. At $500 \mathrm{hPa}$, winds blew seawards, near-surface winds came from the South. Landward winds at $500 \mathrm{hPa}$ coincided with near-surface winds from the North.

At all levels, individual and the composite synoptic maps of retrieved (e.g. Figure 6(b)) and observed funnel cloud events (e.g. Figure 6(a)) were similar in a mesoscale sense. This finding suggests that the retrieval algorithm can identify synoptic situations like those observed during observed funnel cloud events. This means the NWS could use NWP data and the retrieval algorithm to identify these synoptic situations.

\subsection{Anchorage}

The Skew-T diagrams for days with observed funnel cloud events suggested a $500 \mathrm{~m}$ to up to $2 \mathrm{~km}$ deep layer of close to saturation or saturated air and wind shear around this level in the ABL (Figure 2(c), Table 1). All reported funnel cloud events had synoptic scale forcing at 300 and $500 \mathrm{hPa}$ over the region, the southern Yukon Territory and British Columbia (Figure 7(a)). The polar jet was located south of the Gulf of Alaska. At the surface, a low occurred in the Gulf of Alaska.

For the Anchorage region, for most retrieved profiles, the corresponding synoptic maps appeared like the composite synoptic maps of the observed funnel cloud events at all levels. This finding suggests that the algorithm captured situations of same synoptic influence. The composite surface synoptic maps of both retrieved (Figure $7(\mathrm{~b})$ ) and actual funnel cloud situations (Figure $7(\mathrm{a})$ ) were similar in a mesoscale sense.

Only a few retrieved profiles showed a different synoptic situation at 300 and $500 \mathrm{hPa}$ than the composites of observed funnel cloud events. However, their synoptic scale forcing was still weak like for the composites of observed funnel cloud events.

These few different synoptic situations may be false alarms. A comparison of the synoptic situation of each retrieved potential funnel cloud situation with the composite synoptic situation of observed funnel cloud events permits discarding 

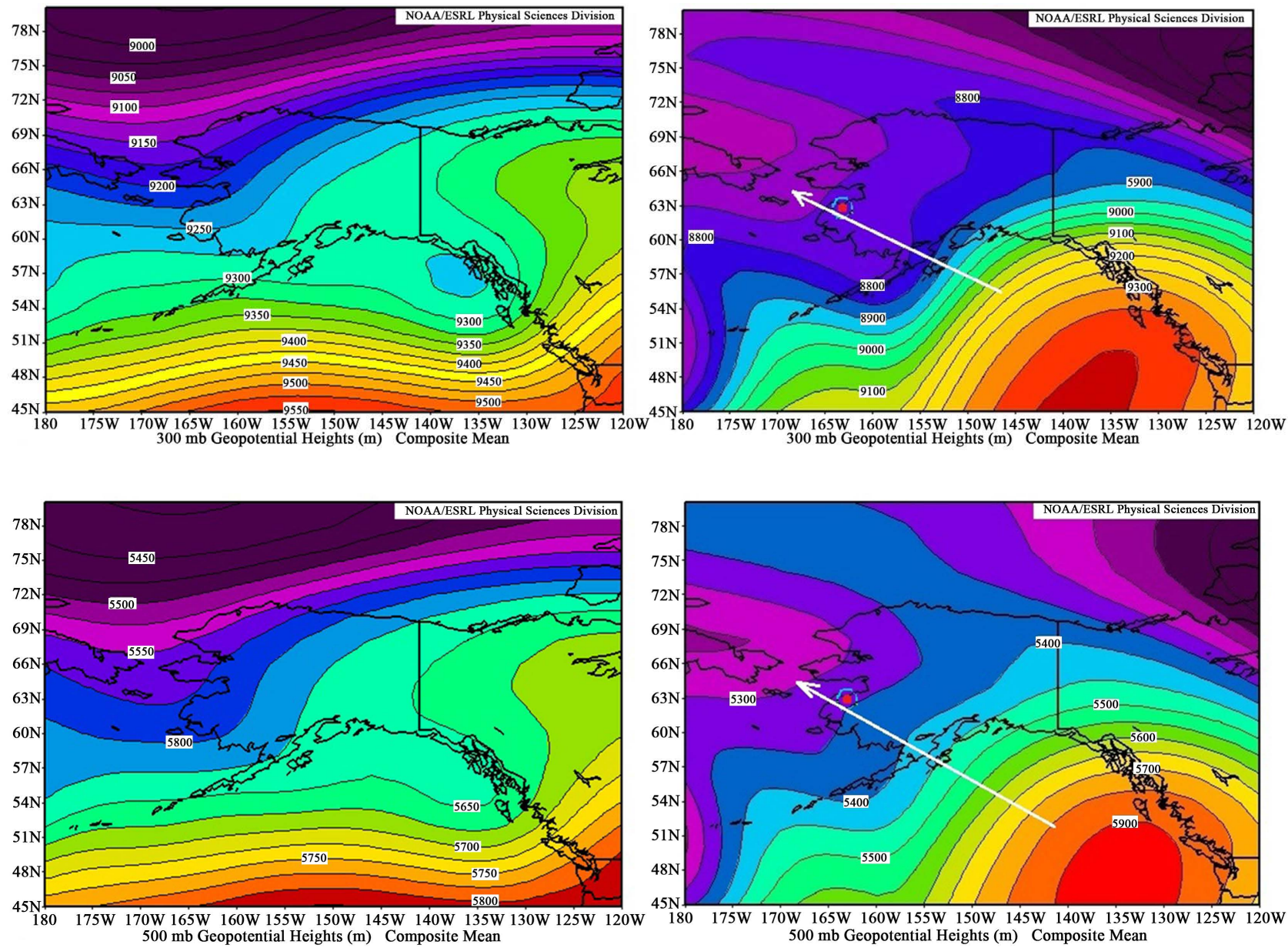

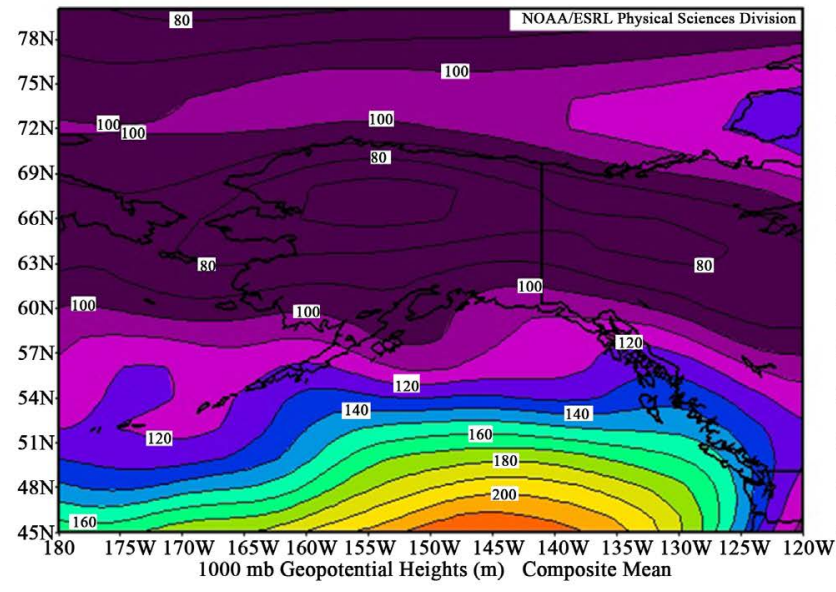

(a)

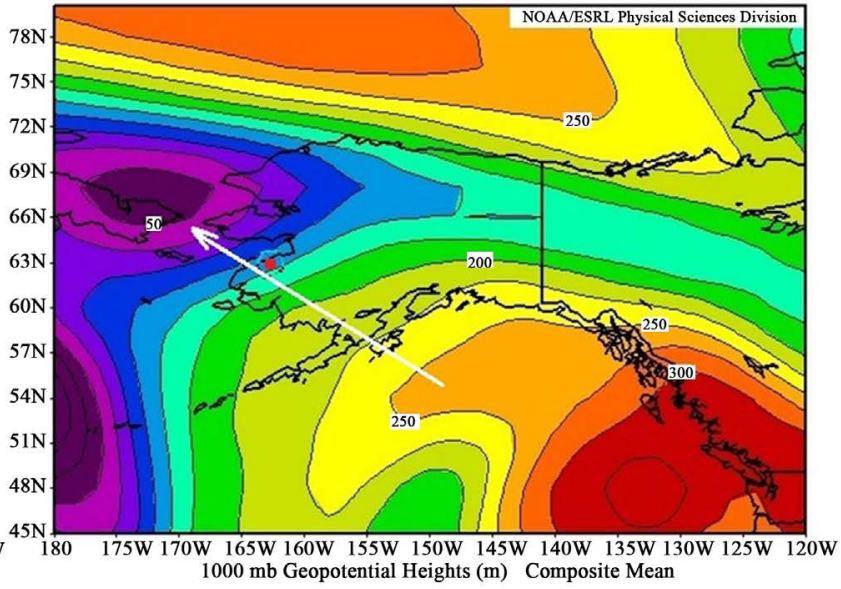

(b)

Figure 6. Composites of reanalysis data showing geopotential heights at $300 \mathrm{hPa}$ (top panel), $500 \mathrm{hP}$ (middle panel), and $1000 \mathrm{hPa}$ (lower panel) on days of (a) observed; and (b) retrieved funnel cloud events around Bethel in the Alaska West Coast region. The synoptic situations for events between Bethel and Nome look similar in a mesoscale sense (therefore not shown).

them. Note that these few different synoptic situations cause some of the differences between the composites of retrieved and observed synoptic conditions (Figure 7(a) and Figure 7(b)). 

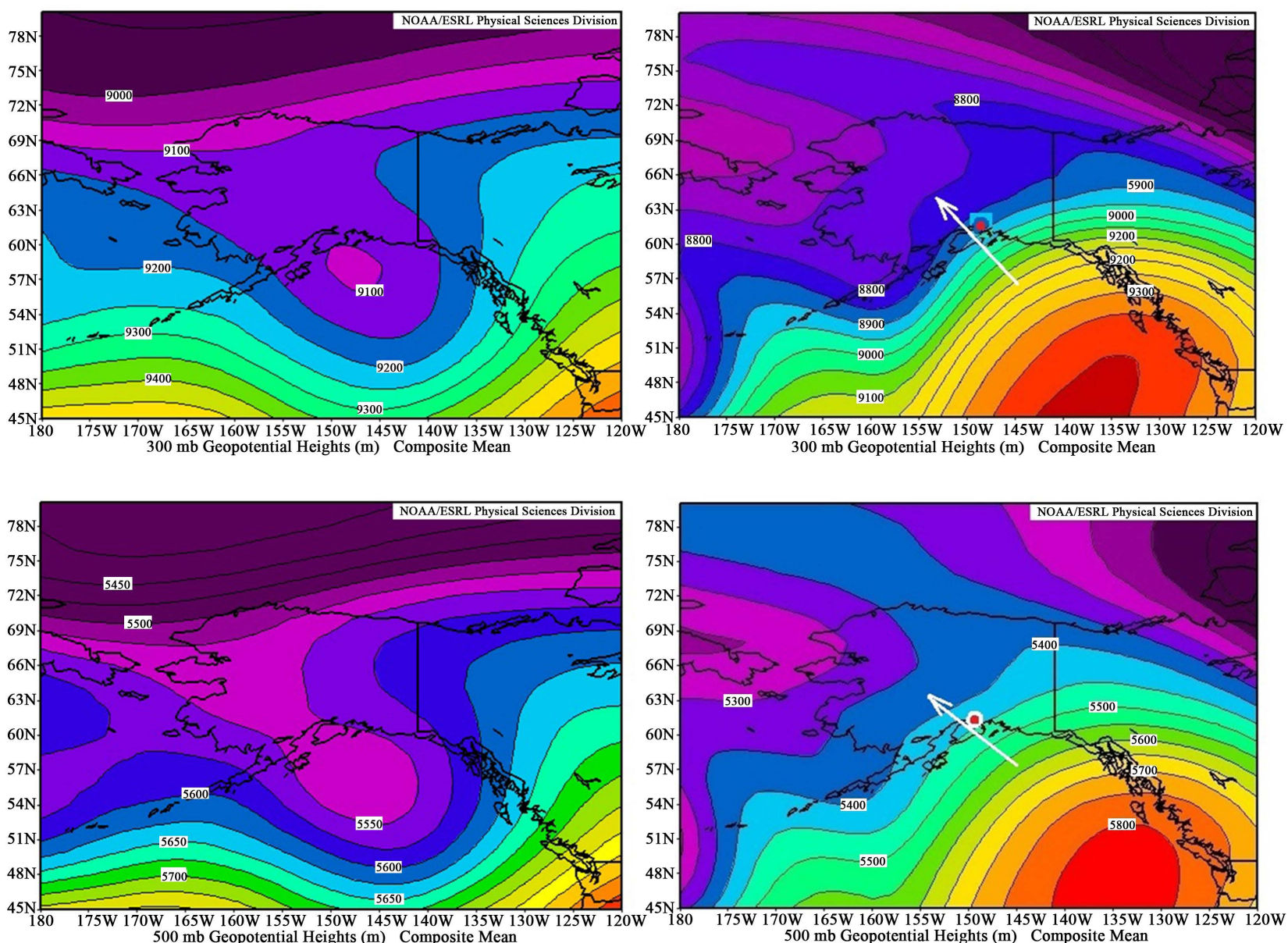

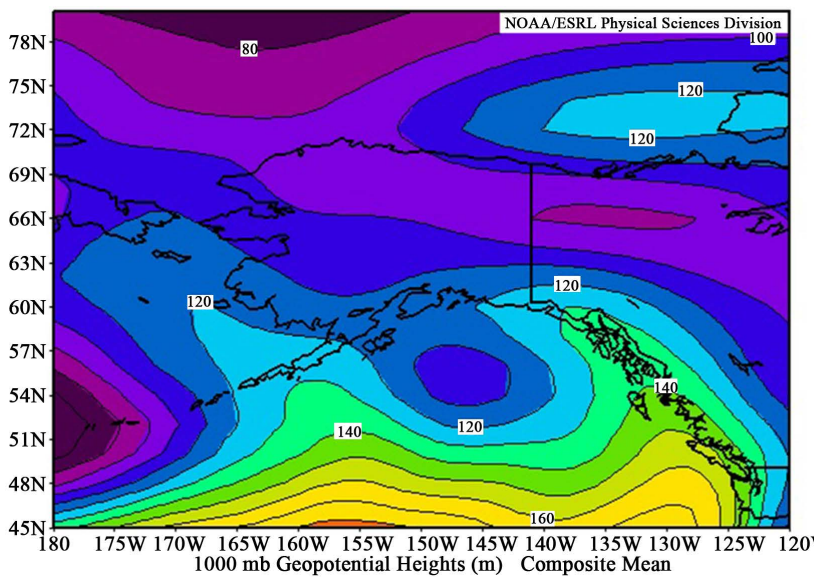

(a)

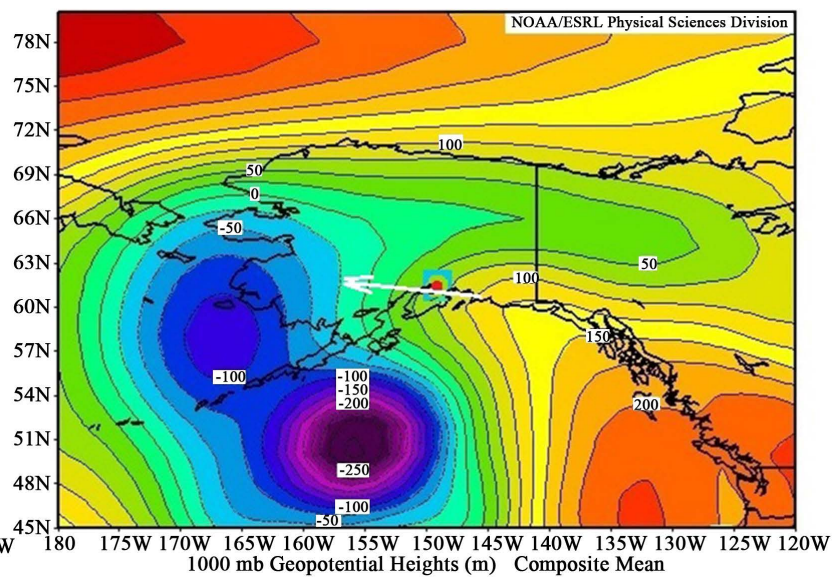

(b)

Figure 7. Composites of reanalysis data showing geopotential heights at $300 \mathrm{hPa}$ (top panel), $500 \mathrm{hP}$ (middle panel), and $1000 \mathrm{hPa}$ (lower panel) on days of (a) observed; and (b) retrieved funnel cloud events for the Anchorage area.

\section{Discussion on Possible Formation Mechanisms}

Since the observed funnel clouds were unlinked to severe thunderstorms, and occurred during weak synoptic conditions, we hypothesize that mesoscale dynamics might cause enough shear instability to generate vorticity for funnel cloud formation. Shear instabilities along the leading edge of density currents, 
such as frontal boundaries, sea-breeze fronts, thunderstorm outflow boundaries or gust fronts can produce small-scale vertical vorticity maxima and areas of enhanced updraft motion or "misocyclones" [14]-[24]. Studying 11 thunderstorm gust fronts with radar and rawinsonde data showed that the intensity of misocyclones was most closely related to the strength of horizontal wind shear across the gust front [22]. Here a series of small-scale $(2-4 \mathrm{~km})$ vertical vorticity maxima spaced at 3 - 7-km intervals occurred. Numerical studies on misocyclone development along thunderstorm outflow boundaries showed that misocyclones distort the horizontal wind field by producing local maxima of low-level convergence northwest and southeast of each circulation center [25] [26]. These low-level convergences can result in enhanced updrafts.

Alternatively to misocylones, as air descents the mountains into a valley with mountain-valley circulation, it generates horizontal vorticity rolls, which when tilted upward lead to vertical vorticity [5]. Such lifting may be due to an updraft, a barrier in the terrain like a hill, or the ascending branch of a sea breeze [24].

\subsection{Interior}

Our analyses of available data suggest terrain-induced mesoscale $\beta / \gamma$ flow interacting with large-scale synoptic flow under weak synoptic scale forcing (Figure $5(\mathrm{a}))$ as the vorticity producing mechanism for funnel clouds in the Interior.

All observed funnel cloud events showed weak to calm winds over the Interior up to $500 \mathrm{hPa}$ in the reanalysis and radiosonde data (cf. Table 1, e.g. Figure 2(a)). Under such weak wind conditions, thermally-driven circulations such as up- and down-valley flow can develop [5] [13] [24] [27]. The landscape of the Interior permits differential surface heating due to local differences in vegetation, terrain elevation, slope orientation and surface properties [4]. Consequently, updrafts (small-scale), slope wind-systems (mesoscale $\gamma$ ), and mountain-valley wind systems (mesoscale $\beta / \gamma$ ) may form.

Figure 8 exemplarily shows the $10 \mathrm{~m}$ wind direction on 22 July 2010 at three sites (Fairbanks, Small Arms Range Alaska, Salcha; see Figure 1 for locations).

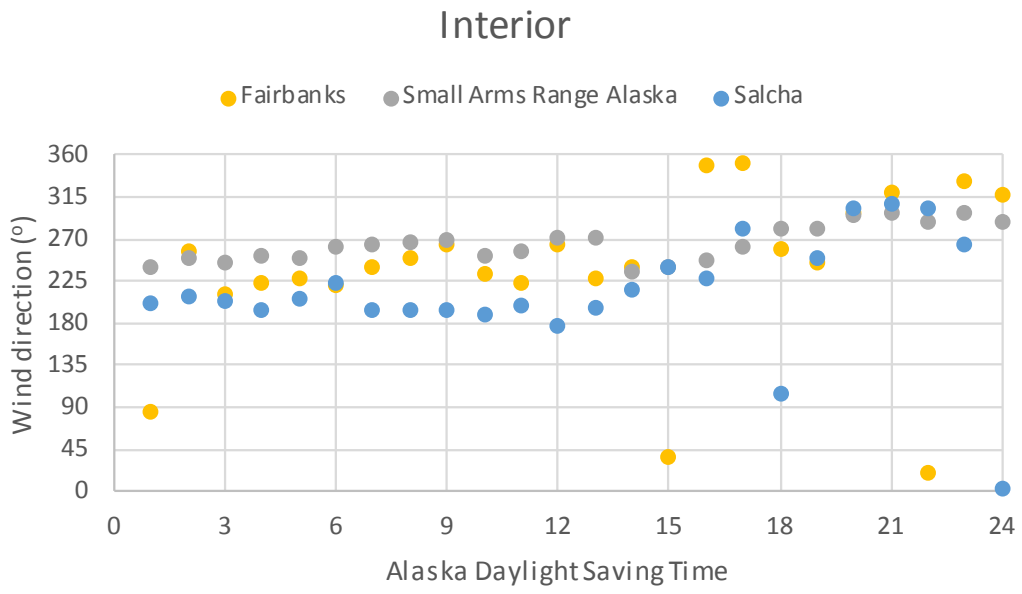

Figure 8. Diurnal course of wind direction (y-axis) in the Interior at three sites on July 22, 2010. The funnel cloud occurred at 9:47 am AKDT. See text for discussion. 
The Salcha site is $\sim 60 \mathrm{~km}$ up-valley from the Fairbanks site. The Small Arms Range Alaska site is $\sim 15 \mathrm{~km}$ from Fairbanks. The valley has a West-East direction at Fairbanks and the range, and a West-Northwest to East-Southeast direction at Salcha. An up-valley flow developed after sunrise (4:17 am AKDT) blowing from westerly directions at Fairbanks and Small Arms Range (Figure 8). The funnel cloud occurred at 9:47 am AKDT over Fairbanks. The valley-mountain wind system broke down in the Fairbanks area around $3 \mathrm{pm}$. Up-valley flow was also found for other funnel cloud events in the Interior.

Given the weak to calm winds (cf. Table 1), any updraft would experience only slight offset from its source at the ground, which constrains the updraft. Chances are good for cloud development when saturation is reached [5]. The dew-point-temperature profiles of the observed funnel cloud events suggested high moisture in the ABL and cloud tops in the upper ABL to mid-troposphere (e.g. Figure 2(a)). The different direction of the wind systems was key in generating the vorticity for the funnel clouds (e.g. Figure 5(a), Figure 8), while the mixing of cool air with warm valley air became essential in cloud formation (Table 1).

The available data suggest the following mechanism for funnel cloud formation in the Interior (Figure 9). Moist air from the Gulf of Alaska is slowly lifted over the glacier-covered Alaska Range. It cools while flowing over the glaciers. Once this cold air descends to the valley floor, it warms, but remains cooler than the warm air that flows up the valley floor (Figure 5(a)). In addition, cold air from above the White or Kuskokwim Mountains (see Figure 1 for locations) may drain down the slopes into the valley (Figure 9). The valley near-surface

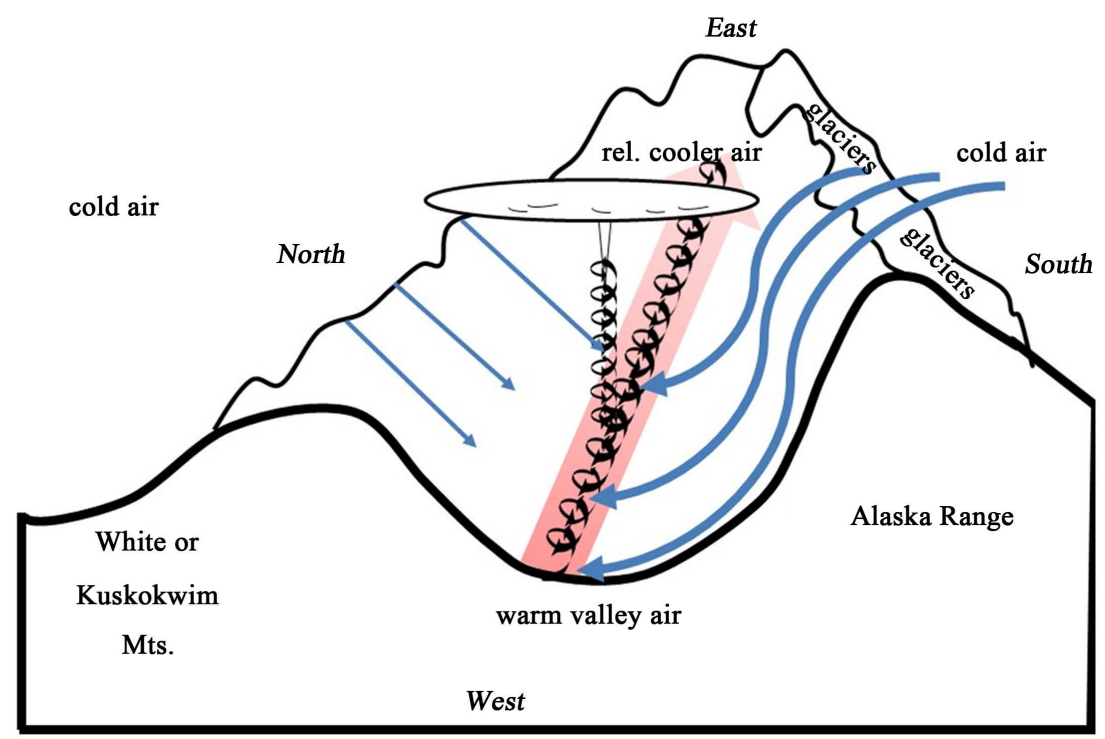

Figure 9. Potential mechanism for funnel cloud formation in the Interior. Gray letters indicate the near-surface conditions of air temperature. Black letters indicate the temperature conditions aloft. The red arrow indicates the up-valley flow with red to pink indicating relatively higher and lower temperatures along the valley. The thick blue arrows indicate the leading edge of the descending air. The thin blue arrows represent downslope winds. Black spirals indicate vorticity tubes. 
winds and cool air moving downslope cause the wind shear. At the same time, air of different hydrothermal properties mixes, which modifies stability and may lead to cloud formation. The wind shear forces the air to rotate in horizontal tubes parallel to the direction of the valley (Figure 9). Buoyancy due to differential heating or slight terrain elevations lifts a rotating tube upward and a rotating updraft forms. Once the lifted air reaches saturation, the rotation becomes visible as funnels.

Alternatively, the cool descending air can act as a density current interacting with the ambient warm up-valley flow forming maxima in vertical vorticity or misocylones along the leading edge of the descending air (Figure 9).

\subsection{Alaska West Coast}

In the Alaska West Coast area, two different scenarios were found: a) An inland wind at the surface with northerly wind at $500 \mathrm{hPa}$, and b) a seaward near-surface wind with southerly wind at $500 \mathrm{hPa}$ flowing parallel to the coast.

Temperature contrasts between land and water may induce a sea-breeze circulation under weak synoptic forcing during the day [5] [13] [24] [27]. Most radiosonde data suggested an inversion in the ABL (e.g. Figure 2(a)). Cold air drainage from mountains or hills can cause a frontal surface along their leading edge [5] [13] [24].

The radiosonde profiles and reanalysis maps of funnel cloud events suggest two scenarios: Funnel clouds form when weak northerly flow exists at mid and upper tropospheric levels and near-surface winds blow from the sea. These conditions are favorable for sea-breeze development (Figure 10). The related wind shear creates the vertical vorticity along the leading edge of the sea-breeze front. During the long daylight hours (white nights), the circulation is barely disrupted.

$\begin{array}{lll} & \text { Q } & 500 \mathrm{hPa} \text { surface warm }\end{array}$
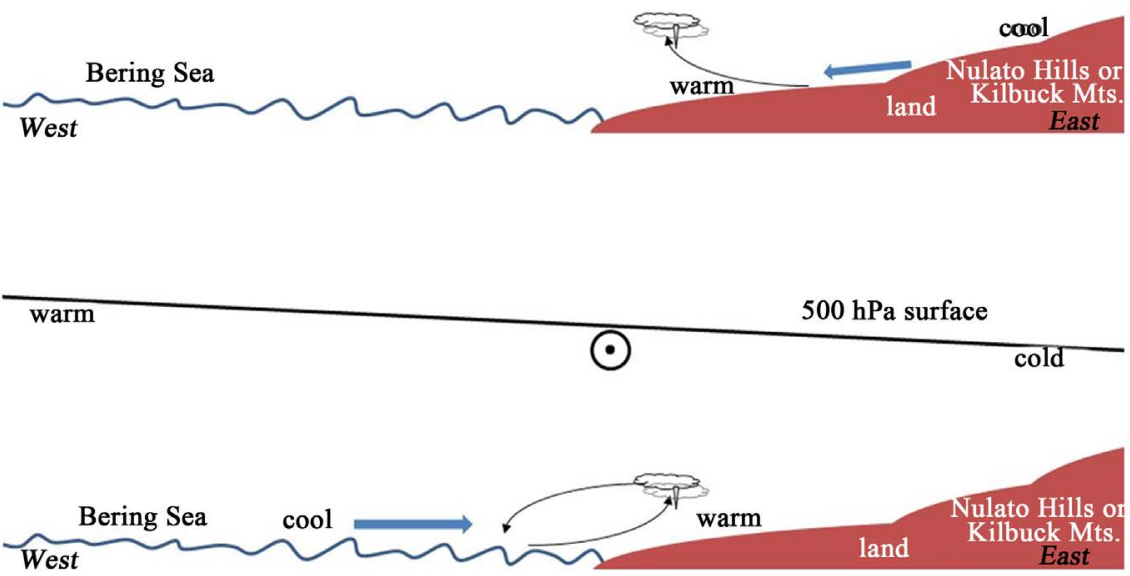

Figure 10. Potential mechanisms for funnel cloud formation in the Alaska West Coast area. 
Funnel clouds also form under weak southerly flow in the mid and upper troposphere when cool air drains down the Nulato Hills or the Kilbuck Mountains and flows into the comparatively warm Yukon River Delta (see Figure 1 for locations). The density current interacts with the relatively lighter, warmer air in the Yukon River Delta forming wind-shear instability, which enhances vertical vorticity or misocylones along its leading edge. Once condensation occurs, funnel clouds can form in areas of enhanced vertical vorticity (Figure 10).

\subsection{Anchorage Region}

The Anchorage region has glacier-covered mountains to one side and ocean to the other. It combines the terrain features that produce horizontal and vertical vorticity in the Interior and Alaska West Coast area. As aforementioned, under weak synoptic scale forcing, mountainous terrain can support formation of slope-wind and mountain-valley systems including katabatic downslope winds [27], while land-ocean contrasts can lead to sea-breeze systems [5] [13] [27]. These systems can interact [28] [29].

Per the reanalysis data and their composites from the observed funnel cloud events (Figure 7(a)) weak synoptic scale forcing is an important pre-requisite for funnel cloud formation in the Anchorage region. Weak synoptic forcing permits development of local mesoscale wind systems that can create vorticity.

In the coastal regions, mountain valley circulations interact with the seabreeze zone to generate horizontal vorticity. At the upward branch, the horizontal vorticity tube is tilted to form vertical vorticity. Farther inland, differential heating of the steep, often glacier-covered mountains causes slope winds and mountain-valley circulations. These wind systems create horizontal shear and vorticity. Cool descending air can act as a density current interacting with the ambient warm up-valley flow forming maxima in vertical vorticity or misocylones along the leading edge of the down-flowing air. Alternatively, terrain induced upward motions or buoyancy turn the horizontal vorticity tube vertical. During ascend cooling can lead to condensation, and rotation becomes visible as funnels.

Unfortunately, all reported funnel cloud events in the Anchorage area were far apart from each other in location (Figure 1) and far away from surface meteorological sites. Thus, examination of the diurnal behavior of wind direction was not possible.

\section{Conclusions}

Funnel cloud reports, surface meteorological, radiosonde, reanalysis and radar data were analyzed to determine the climatology, characteristics, and forming mechanism of funnel clouds observed in the Interior, Alaska West Coast and Anchorage area. Between 1955 and 2014, a total of 43 funnel clouds occurred. Most sightings occurred between 11 am and 6 pm AKDT between May and September with July having the highest number of events. All funnel cloud events close to the launch time and site had CAPE of $\sim 500 \mathrm{~J} \cdot \mathrm{kg}^{-1}$ or more. 
In all three regions, funnel clouds occurred under weak synoptic scale forcing throughout the troposphere over the respective region. All radiosonde Skew-T/ log-p diagrams and radar analyses indicated that Alaska funnel clouds are non-supercell thunderstorm clouds and owe their vorticity to wind shear in the ABL. Here, an approximately $500-2000 \mathrm{~m}$ thick layer of moist air was present while air was dry aloft.

Interaction between mesoscale dynamics of different scales created wind shear and the required vertical vorticity for funnel cloud formation in the ABL under specific weak synoptic scale (mesoscale $\alpha$ ) forcing conditions. These synoptic situations depend on the region and can be identified from surface observations, mid- and upper-level synoptic maps, and radiosonde profiles.

Local scale dynamics creates horizontal vortex tubes either by a combination of a valley wind with slope winds (Interior) or a combination of slope or mountain-valley wind systems and sea-breeze circulation (Anchorage region). Differential heating due to the spatial patchiness of the land-cover, land-sea contrast, and different insolation of slopes creates buoyancy. Updrafts or forced lifting in uneven terrain or at surface discontinuities tilt the horizontal vortex tube into a vertical one. Adiabatic cooling during lifting and mixing of air cool, dry, descending air with moist, warm, ascending air lead to saturation and cloud formation at the top of the ABL, i.e. Alaska funnel clouds are boundary layer clouds.

In the Alaska West Coast area, two situations occur: a) The synoptic-scale wind field and land-sea contrast create the horizontal vortex tube that is tilted by the upward branch of the sea breeze. b) The synoptic-scale wind field and density flow from cold air drainage off the Nulato Hills or Kilbuck Mountains create the vertical vorticity.

A similarity retrieval algorithm was introduced by defining limits for temperature, dew-point temperature, and wind profiles and a minimum CAPE from soundings during funnel cloud events. Soundings that met the limits and requirement were considered retrieved funnel cloud events. In the Interior, $2 \%$ of the soundings between May to September 1971 to 2014 indicated potential funnel cloud events between Fairbanks and McGrath, a mostly unpopulated area. Potential for funnel cloud events was less in all other regions. Given the large fraction of unpopulated areas in Alaska, events may occur, but remain unobserved.

Alaska's population increased from 547,160 in 1989 to 736,732 in 2014 [30]. Based on the results of the similarity retrieval algorithm, the number of potential funnel cloud situations decreased after 2000 as compared to prior to 1989. This finding suggests that the increase in reported funnel cloud events after 2000 may be due to the increase in population and devices for documentation. Our results further suggest that the NWS record certainly under-represents past events.

The resolution of operational radars is too coarse to serve for funnel cloud warnings unless the event occurs close enough to the radar. However, the similarity of composites based on retrieved and observed funnel cloud events suggests that the retrieval algorithm can identify synoptic situations suitable for 
funnel cloud development. This finding is very important for development of funnel cloud forecasts and warnings. Forecasters could use radiosonde data together with synoptic analysis maps to identify days favorable for funnel cloud formation. In addition, the retrieval algorithm could be modified to run with NWP model forecasted vertical profiles to test whether the forecasted synoptic situation may be suitable for funnel cloud formation. However, as to what extent in lead-time such forecasts would be possible, would be subject to further research.

Future field studies should focus on vorticity development in the ABL to ascertain the exact forcing and winds necessary for funnel cloud development. Given the scarcity of reported and potential funnel cloud events, a targeted field campaign is rather difficult. Since such campaigns need at least a year or more in lead-time, we suggest establishing a monitoring network of at least nine wind profilers between Fairbanks and McGrath where most of the observed (Figure 1) and retrieved potential funnel cloud events occurred. For synoptic situations identified as supportive for funnel cloud formation in this area, the data could be screened for vorticity. Data from the cloud radar at Ft. Greely (Figure 1) that became available in 2015 could serve to examine cloud microphysical properties and cloud vertical extension where the beam is not blocked by mountains. Analyses of such data together with the radiosonde data at McGrath and Fairbanks could shorten the lead-time for the forecast of funnel clouds.

\section{Acknowledgements}

We thank G. Kramm, U.S. Bhatt, R.L. Collins and the anonymous reviewers for fruitful discussion and helpful comments, NOAA for access to the radiosonde and radar data, the National Center for Atmospheric Research for access to the reanalysis data, the National Science Foundation (NSF), the SOARS program, the Gwichyaa Zhee Gwich' in Tribal Government, and SLOAN for financial support.

\section{References}

[1] Edwin, S.G. (2016) Climatology and Forcing Mechanism of Funnel Clouds in Alaska. MS Thesis, Department of Atmospheric Sciences, University of Alaska Fairbanks, Fairbanks.

[2] von Storch, H. and Zwiers, F.W. (1999) Statistical Analysis in Climate Research. Cambridge University Press, Cambridge, 484 p.

[3] Shulski, M. and Wendler, G. (2007) The Climate of Alaska. University of Alaska Press, Fairbanks, 216 p.

[4] Mölders, N. and Kramm, G. (2007) Influence of Wildfire Induced Land-Cover Changes on Clouds and Precipitation in Interior Alaska-A Case Study. Atmospheric Research, 84, 142-168. https://doi.org/10.1016/j.atmosres.2006.06.004

[5] Lin, Y.-L. (2007) Mesoscale Dynamics. Cambridge University Press, Cambridge. https://doi.org/10.1017/CBO9780511619649

[6] Houze, R.A. (2014) Cloud Dynamics. Vol. 104, Academic Press, Cambridge.

[7] Department of Commerce (2014) Stormevents. 
http://www.ncdc.noaa.gov/stormevents/listevents.jsp?eventType=\%28C\%29+Funne $1+$ Cloud\&beginDate_mm $=05 \&$ beginDate_dd $=01 \&$ beginDate_yyyy $=1971$ \&endDate _mm $=08 \&$ endDate_dd $=30 \&$ endDate_yyyy $=2014 \&$ county $=$ ALL\&hailfilter $=0.00 \&$ to $\underline{\text { rnfil- }}$

ter $=0$ \&windfilter $=000 \&$ sort $=$ DT \&submitbutton $=$ Search\&statefips $=2 \% 2$ CALASKA

[8] Bieniek, P.A., Walsh, J.E., Thoman, R.L. and Bhatt, U.S. (2014) Using Climate Divisions to Analyze Variations and Trends in Alaska Temperature and Precipitation. Journal of Climate, 27, 2800-2818. https://doi.org/10.1175/JCLI-D-13-00342.1

[9] Kalnay, E., Kanamitsu, M., Kistler, R., Collins, W., Deaven, D., Gandin, L., et al. (1996) The NCEP/NCAR 40-Year Reanalysis Project. Bulletin of the American Meteorological Society, 77, 437-471. https://doi.org/10.1175/1520-0477(1996)077<0437:TNYRP>2.0.CO;2

[10] Kistler, R., Collins, W., Saha, S., White, G., Woollen, J., Kalnay, E., et al. (2001) The NCEP-NCAR 50-Year Reanalysis: Monthly Means CD-Rom and Documentation. Bulletin of the American Meteorological Society, 82, 247-267. https://doi.org/10.1175/1520-0477(2001)082<0247:TNNYRM>2.3.CO;2

[11] Office of the Federal Coordinator for Meteorological Services and Supporting Research (OFCM) (1997) Federal Meteorological Handbook No. 3: Rawinsonde and Pibal Observations. FCM-H3-1997, Washington DC, 191 p.

[12] Pielke, R.A. (2002) Mesoscale Meteorological Modeling. Academic Press, New York, $676 \mathrm{p}$.

[13] Mölders, N. (2011) Land-Use and Land-Cover Changes: Impact on Climate and Air Quality. Vol. 44, Springer Science \& Business Media, Berlin, 193 p.

[14] Fujita, T.T. (1981) Tornadoes and Downbursts in the Context of Generalized Planetary Scales. Journal of Atmospheric Sciences, 38, 1511-1534. https://doi.org/10.1175/1520-0469(1981)038<1511:TADITC >2.0.CO;2

[15] Carbone, R.E. (1982) A Severe Frontal Rainband. Part I: Stormwide Hydrodynamic Structure. Journal of Atmospheric Science, 39, 258-279. https://doi.org/10.1175/1520-0469(1982)039<0258:ASFRPI>2.0.CO;2

[16] Mueller, C.K. and Carbone, R.E. (1987) Dynamics of a Thunderstorm Outflow. Journal of Atmospheric Sciences, 44, 1879-1898. https://doi.org/10.1175/1520-0469(1987)044<1879:DOATO>2.0.CO;2

[17] Wakimoto, R.M. and Wilson, J.W. (1989) Non-Supercell Tornadoes. Monthly Weather Review, 117, 1113-1140. https://doi.org/10.1175/1520-0493(1989)117<1113:NST>2.0.CO;2

[18] Weckwerth, T.M. and Wakimoto, R.M. (1992) The Initiation and Organization of Convective Cells Atop a Cold-Air Outflow Boundary. Monthly Weather Review, 120, 2169-2187. https://doi.org/10.1175/1520-0493(1992)120<2169:TIAOOC >2.0.CO;2

[19] Wilson, J.W., Foote, G.B., Crook, N.A., Frankhauser, J.C., Wade, C.G., Tuttle, J.D., et al. (1992) The Role of the Boundary-Layer Convergence Zones and Horizontal Rolls in the Initiation of Thunderstorms: A Case Study. Monthly Weather Review, 120, 1785-1815. https://doi.org/10.1175/1520-0493(1992)120<1785:TROBLC >2.0.CO;2

[20] Kingsmill, D.E. (1995) Convection Initiation Associated with a Sea-Breeze Front, a Gust Front, and Their Collision. Monthly Weather Review, 123, 2913-2933. https://doi.org/10.1175/1520-0493(1995)123<2913:CIAWAS>2.0.CO;2

[21] Arnott, N.R., Richardson, Y.P., Wurman, J.M. and Rasmussen, E.M. (2006) Relationship between a Weakening Cold Front, Misocyclones, and Cloud Development 
on 10 June 2002 during IHOP. Monthly Weather Review, 134, 311-335. https://doi.org/10.1175/MWR3065.1

[22] Friedrich, K., Kingsmill, D.E. and Young, C.R. (2005) Misocyclone Characteristics Along Florida Gust Fronts during CAPE. Monthly Weather Review, 133, 33453367. https://doi.org/10.1175/MWR3040.1

[23] Murphey, H.V., Wakimoto, R.M., Flamant, C. and Kingsmill, D.E. (2006) Dryline on 19 June 2002 during IHOP. Part I: Airborne Doppler and LEANDREII Analyses of the Thin Line Structure and Convection Initiation. Monthly Weather Review, 134, 406-430. https://doi.org/10.1175/MWR3063.1

[24] Mölders, N. and Kramm, G. (2014) Lectures in Meteorology. Springer, Heidelberg, $591 \mathrm{p}$.

[25] Lee, B.D. and Wilhelmson, R.B. (1997) The Numerical Simulation of Non-Supercell Tornadogenesis. Part I: Initiation and Evolution of Pretornadic Misocyclone Circulation along a Dry Outflow Boundary. Journal of Atmospheric Science, 54, 32-60. https://doi.org/10.1175/1520-0469(1997)054<0032:TNSONS>2.0.CO;2

[26] Lee, B.D. and Wilhelmson, R.B. (1997) The Numerical Simulation of Non-Supercell Tornadogenesis. Part II: Evolution of a Family of Tornadoes along a Weak Outflow Boundary. Journal of Atmospheric Science, 54, 2387-2415. https://doi.org/10.1175/1520-0469(1997)054<2387:TNSONT>2.0.CO;2

[27] Bluestein, H.B. (1985) An Observational Study of a Mesoscale Area of Convection under Weak Synoptic-Scale Forcing. Monthly Weather Review, 113, 520-539. https://doi.org/10.1175/1520-0493(1985)113<0520:AOSOAM>2.0.CO;2

[28] Kondo, H. (1990) A Numerical Experiment on the Interaction between Sea Breeze and Valley Wind to Generate the So-Called "Extended Sea Breeze". Journal of the Meteorological Society of Japan, 68, 435-446. https://www.jstage.jst.go.jp/article/jmsj1965/68/4/68_4_435/_pdf

[29] Kurita, H., Ueda, H. and Mitsumoto, S. (1990) Combination of Local Wind Systems under Light Gradient Wind Conditions and Its Contribution to Long-Range Transport of Air Pollutants. Journal of Applied Meteorology, 29, 331-348. https://doi.org/10.1175/1520-0450(1990)029<0331:COLWSU>2.0.CO;2

[30] US Census (2017). https://www.census.gov/

\section{Scientific Research Publishing}

Submit or recommend next manuscript to SCIRP and we will provide best service for you:

Accepting pre-submission inquiries through Email, Facebook, LinkedIn, Twitter, etc. A wide selection of journals (inclusive of 9 subjects, more than 200 journals)

Providing 24-hour high-quality service

User-friendly online submission system

Fair and swift peer-review system

Efficient typesetting and proofreading procedure

Display of the result of downloads and visits, as well as the number of cited articles

Maximum dissemination of your research work

Submit your manuscript at: http://papersubmission.scirp.org/

Or contact acs@scirp.org 